\title{
النظام المصرفي في الدولة الإسلامية
}

\section{دراسة تاريخية}

\section{*خالد إسماعيل نايف الحمدالي}

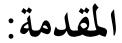

نالت الدراسات السياسية والإدارية والعسكرية في التاريخ الإسلامي حظاً موفوراً واهتماماً كبيراً من قبل

الباحثين المهحدثين، فنجد كماً هائلاً من دراسات التاريخ الإسلامي اهتمت بالجوانب المذكورة، ولا زالت جوانب أخرى في التاريخ الإسلامي بحاجة إلى مزيد من الدراسة والبحث ومنها على سبيل المثال: الجوانب الفكرية والاقتصادية والاجتماعية. ومن هنا جاءت هذه المحاولة في التاريخ الاقتصادي لإبراز الأثر الاقتصادي للصيارفة في الدولة الإسلامية منذ نشأها حتى القرن الرابع الهجري.

ويجد الباحث معلومات متناثرة عن الصيرفة في كتب التاريخ العام ومعلومات أكثر في كتب النظم المختلفة خاصة الإدارية والمالية، وكذا تناولتها كتب الأدب واهتمت بها كتب الفقه من حيث بيان الوجه الصحيح في التعامل المصرين، واعتنت بها أيضاً كتب الحسبة والأموال إ من بين مهام المحتسب مراقبة الصيارفة، واهتمت بها الدراسات الحديثة فهي وإن كانت قليلة ولكنها مهمة نذكر منها دراسة الدكتور عبد العزيز الدوري: تاريخ العراق الاقتصادي في القرن الرابع الهجري، الذي تناول الجهبذة والصيرفة وتطوها حتى القرن الرابع الهجري، وتتناولها أيضاً الأستاذ الدكتور عبد الجميد الكبيسي في بعض دراساته خاصة: "أسواق بغداد حتى العصر البويهي"، و"أصول النظام النقدي"، وتناولتها الدكتورة أمل عبد الحسين عباس باهتمام أكبر في رسالتها للدكتوراه في جامعة بغداد عنوان: "الصيرفة والجهبذة في العراق من القرن الثاني حتى القرن الرابع الهجري". 
ونظراً لأهمية الموضوع والرغبة في مواصلة جهد من سبق جاء هذا البحث لإبراز قضية مهمة في التاريخ الاقتصادي تتبعنا فيها المعنى اللغوي والاصطلاحي للصيرفة والصيارفة والصراف. ثم تناول البحث التطور التاريخي للصيرفة وأنواع الصيرفة في الدولة الإسلامية والمهام التي تكفل بها الصيارفة. وتناول البحث اهتمام مسؤولي الدولة الإسلامية بالصيرفة وأثر الصيرفة في استقرار النشاط الاقتصادي وازدهاره في الدولة الإسلامية.

\section{معنى المصرف لغة واصطلاحاً:}

يمكن التوصل إلى المعنى اللغوي لكلمة المصرف من خلال معرفة معنى الصراف والصيرفي والصيرف. فهي جميعاً تأتي بمعنى صرف الدراهم 1 أي الذي يقوم بتصريفها، وهي أيضاً"فضل الدرهم على الدرهم والدينار على الدينار"2 وما كانت العملة الفضية (الدراهم) والذهبية (الدينار) هي السائدة في الدولة العربية الإسلامية فقد جاء معنى الصرف أيضاً"بيع الذهب بالفضة"3 وجاءت بمعنى تحويل العملة "صرف الدراهم بالدنانير". 4 ويستعمل الصرف بين العملة الواحدة أيضاً: يقال: "بين الدرهمين صرف أي فضل لجودة فضة

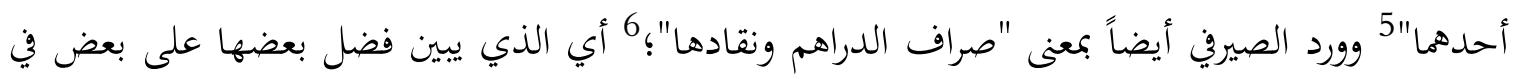
القيمة والنقاوة والجودة. ويفهم مما تقدم أن معنى الصرف لغوياً هو تبديل العملات النقدية وتحويلها من عملة إلى أخرى أو نقد العملة الواحدة، ومن هنا يبرز معنى المصرف فهو المكان الذي تتم فيه علية الصرف المذكورة أعلاه. فنرى أن الصيرفة مهنة قائمة بذاتما تميزت عن المهن الأخرى لكوها اختصت بالقيمة النقدية للأشياء، والصيريف هو الشخص الذي اتخذ الصيرفة مهنة وكسباً له قائمة على أساس التعامل النقدي.

أما معنى الصراف اصطلاحاً فكثرت الأقوال فيه وأبدى كل رأيه حسب اختصاصه وعلمه، وسنذكر هنا بعض الأقوال المشهورة لأناس من مختلف ضروب المعرفة والاختصاص متأثرين بأعمالهم وعلومهم، فأُطلق مثلاً اسم الفلاس على الصيرفي ويعني به الشخص الذي اتخذ عملية بيع النقود مهنة خاصة به، و"الفلاس

$$
\begin{aligned}
& 1 \\
& 2 \\
& \text { 3 } \\
& 4 \\
& \text { } 5 \\
& \text { 6 }
\end{aligned}
$$


هذه نسبة إلى من يبيع الفلوس وكان صيرفياً" وأورد السمعاني 8 وهو الذي ركز على الأنساب رأيه فقال" الصراف. . . هذه نسبة لجماعة يبعون الذهب بالفضة أو يزنون ويبعون الذهب بالذهب متفاضلاً"، والصيرفي عند الفقهاء هو بيع الثمن بالثمن جنساً بجنس كبيع الذهب بالذهب أو بغير جنس كبيع الذهب الفضة، 9 وورد عند آخرين منهم بمعنى عقد بيع تكون فيه السلع المتبادلة من معدن نفيس، 10 وقال النسفي "الصرف فضل الدرهم على الدرهم، ومنه اشتق اسم الصيرفي، والصراف لتصريفه بعض ذلك في بعض 11 وذكر القلقشندي، 12 صاحب كتاب صبح الأعشى في فن الإنشاء، أنَّ الصيرفي الذي يتولى قبض الأموال وصرفها وهو مأخوذ من الصرف وهو صرف الذهب والفضة في الميزان"، ويسمى أحياناً الناقد أو الناقذي، بكري، إذ ورد "خذوا من فلان الناقد وفلان كل ما عندهما من الورق والعين الساعة". 13 ومن المتمل أن يكون إضفاء هذه التسمية على الصراف تشبهاً بنقد الحديث وغربلته لبيان صحته وذلك لتشابه عمل الاثنين الذي يتطلب الدقة والتمحيص والتثبيت قبل إبداء الرأي. وخلط بعض الباحثين بين الجهبذ والصراف فنراهم يطلقون أحياناً كلمة الجهبذة والجهابذة على الصرافين والجهبذ في الأصل هو كاتب خراج معروف زمن الساسانيين وكان هذا معروفاً للمسلمين في العصر الأموي والعباسي واستعان بعض الولاة بالجهابذة لجباية الضرائب في بعض المقاطعات، وفي القرن الثالث الهجري (التاسع الميلادي) تطوّر استخدام هذه الكلمة إذ تحوّل بعض الجهابذة من كتاب خراج إلى أصحاب بيوت مالية وذلك على إثر تعيين بعض التجار لجهبذة بعض المناطق مثل تعيين يوسف بن فنجاس جهبذاً للأهواز في وزارة علي بن الفرار الأولى (296-299هـ/908-910م). والغاية من تعيين هذا التاجر جهبذاً هو حاجة الدولة إلى المال قبل موعد الجباية فيقوم الجهبذ بتسليفها ثم يستوفي أمواله بعدئذ من ضرائب الأهواز 14 فبدأ الجهابذة

$$
\begin{aligned}
& 7
\end{aligned}
$$

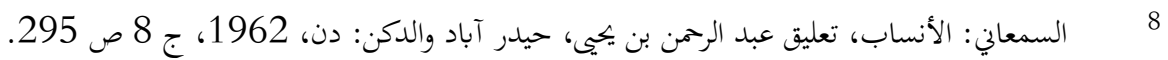

$$
\begin{aligned}
& 99 \\
& 10
\end{aligned}
$$

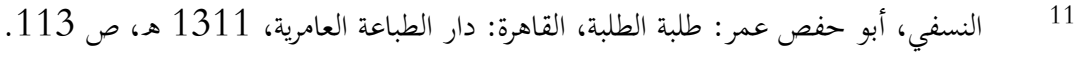

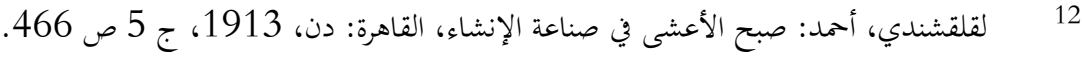

$$
\begin{aligned}
& 13 \text { } 14
\end{aligned}
$$

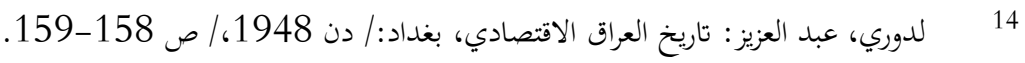


يمارسون أعمال الصرافين، وبدأ الجهبذ يعرف بأنه (الناقذ الحبير بغوامض الأمور والعارف بطرق النقد)15 فمن المتمل أن يكون هذا الخلط بين الصيرفة والجهبذة ناجماً عن تقارب وتمازج الحرفتين وتعامل كل منهما

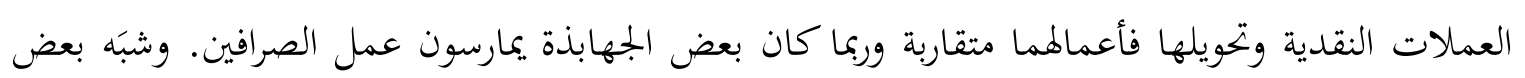
المؤرخين المحدثين الصرافين بأصحاب البنوك وعملهم بعمل البنوك الحديثة، 16 وخالفهم آخرون في الرأي فأكدوا أنم المصارف في العهد العباسي تختلف اختلافاً كبيراً عن المصارف الحديثة من حيث أن أغلبها مصارف خاصة يملكها الأفراد وأن أعمالها أقل تخصصاً من المصارف الحديثة. 17

\section{التطور التاريخي للنظام المصرفي في الدولة الإسلامية:}

ترجع ممارسة مهنة الصيرفة في البدان العربية إلى حقب تاريخية متقدمةى، فكان سكان العراق القدماء سباقين إلى ممارسة هذه المهنة، إذ زوال العراقيون القدماء الصيرفة كأساس لتنظيم حياتم الاقتصادية، وأفراد حمورابي (1686-1728ق.م) في شريعته ما يقارب 120 مادة من مجموع 282 مادة للمعاملات المالية والشؤون التجارية من بينها المعاملات المصرفية والائتمان وأمور التجارة والاستثمار وغيرها من المعاملات 18 المالية.

وعثر على مجموعة من الرقم الطينية في العهد الآشوري في حدود منتصف الألف الثاني (ق. م) تدور

حول معاملات مصرفية خاصة بالائتمان التجاري والبيع الآجل، 19 واشتهرت عائلة آل يجبيي في عهد البابليين بأعمالمم المصرفية التي بدأت عام (685 ق. م) واستمرت حوالي أربعمائة سنة وكانوا يقومون بالنسيئة والتحويل والعقود التجارية والمالية والقروض من مدينة إلى أخرى. 20

$$
\begin{aligned}
& 15 \text { } 15 \\
& 1617 \\
& 17 \text { } 18
\end{aligned}
$$

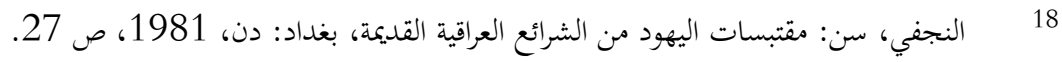

$$
\begin{aligned}
& 19 \\
& 20
\end{aligned}
$$


واستمر النشاط المصريف في العراق وهذا ما نلمسه من نشاط المدائن في الفترة التي سبقت الإسلام في مجال التبادل التجاري والمعالات المصرفية المتعلقة بتبادل العملات المتداولة وهي المسكوكات الفضية والذهبية ثم نقل الصيارفة مركزهم إلى الكوفة في العهد الإسلامي.21 ولم تقتصر ممارسة الصيرفة على سكان العراق بل عرفها العرب في الجزيرة العربية قبل الإسلام فكانت أبرز النشاطات الائتمانية التي مارسها العرب هي المصرف والصيرفة، 22 وبرزت من بينهم فئة تخصصت في هذه الحرفة مستفيدين من موقعهم المتوسط بين الساسانيين الذين كانت عملتهم الفضة والبيزنطيين الذين استخدموا العملة الذهبية فأخذ العرب يقومون بأعمال الصيرفة، 23 فكانت هذه المهنة مصدراً مهماً من مصادر تراكم الثروة لديهم ومصدراً لتحويل النشاطات التجارية والزراعية في الوقت نفسه، وهناك إشارات إلى وجود صرافين في أسواق المدن العربية قبل الإسلام مثل مكة ويثرب والحيرة والأنبار وغيرها. 24 وعند ظهور الإسلام في بلاد العرب وقيام الدولة الإسلامية أباح الدين الإسلامي التعامل المصريف، فقد سأل بعض الصحابة الرسول الكريم عن الصرف فأجاب: ((إن كان يداً بيد فلا بأس ولا يصلح نسيئة، 25 وقال أيضاً: "لا تبيعوا الذهب بالذهب إلا مثلاً بمثل ولا تشقوا بعضها ببعض 26 "وورد عنه: ((الورق بالذهب ربًا ألا هاء وهاء)).27 وقد مارس عدد ن الصحابة مهنة الصيرفة منهم الزبير بن العوام الذي كان يأخذ الورق من التجار ويكتب لهم سفاتج إلى البصرة والكوفة فيأخذون أجود من ورقهم، 28 وكذلك ورد عن عبد الله بن عباس أنه كان يأخذ الورق بمكة من التجار والمسافرين على أن يكتب لهم إلى الكوفة ليأخذوا مثل ورقهم.

$$
\begin{aligned}
& 21
\end{aligned}
$$

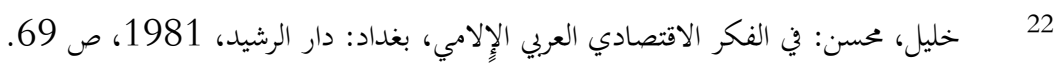

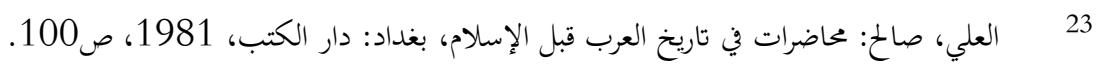

$$
\begin{aligned}
& 24 \\
& 25 \text { 2 } 25
\end{aligned}
$$

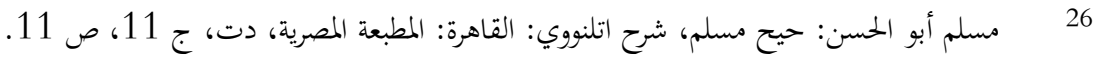

$$
\begin{aligned}
& 27 \text { 2 } 28 \\
& 28 \text { 2 } 28 \\
& 2928
\end{aligned}
$$


وبعد اتساع الدولة الإسلامية وتمصير الأمصار نشطت المعاملات المصرفية في المدن العربية تبعاً للاستقرار الاقتصادي الناجم عن الرخاء والازدهار السياسي والاقتصادي للدولة، فنشطت الصيرفة في أسواق المدن مثل البصرة والكوفة والفسطاط والقيروان وواسط وبغداد وسامراء وغيرها من المدن الإسلامية30 وكان للكوفة دور بارز في المعاملات المصرفية وازدهارها إذ أن صرافي المدائن انتقلوا بعد الفتح الإِالامي للعراق إلى الكوفة وعاودوا نشاطهم المصريف وكان لذلك أثر طيب على الكوفة إذ نظمت أعمال الصيارفة وأتقنت المهنة وكان لصيارفها فضل كبير في تقدم الصيرفة في العراق وفي بغداد بشكل خاص. 31 ووصل النشاط المصريف أقصاه في بغداد بعد بنائها حيث أصبحت مركزاً لدولة مترامية الأطراف فكثر سكاها، وتنوعت معاملاتما المالية بالإضافة إلى تعداد دور الضرب وتسرب الموال الأجنبية إليها، كل ذلك ساعد على إنعاش أعمال المصارف في بغداد.

وكانت الصيرفة تمارس ن قبل الصرافين ومن قبل الدولة أيضاً حيث كان بيت المال بمثابة مصرف رسمي

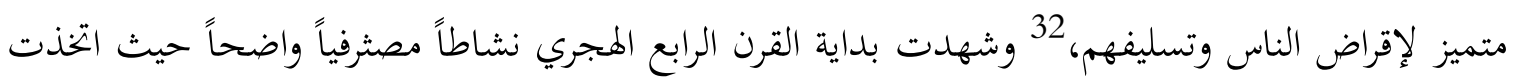
المصارف بشكل بيوت مالية أوجدها ضرورات النشاط التجاري، وكذلك لتعامل المسؤولين مع تلك المؤسسات، 33 وانتشرت المصارف انتشاراً كبيراً في أنحاء الدولة الإسلامية فأصبح في كل مدينة مصرف، بل أصبحت هناك أسواق مخصصة للصيارفة مثل سوف درب العيون في الكرخ ببغداد، 34 وازدحم الصرافون في أسواقهم فأورد ناصر خسرو في (رحلته) انه كان بسوق الصرافين بمدينة أصفهان مائتا صراف وكانوا جميعاً يجلسون في سوق واحدة تسمى سوق الصرافي، 35 بالإضافة إلى ذلك كان للمصارف فروع في مدن أخرى فعمل ذلك على زيادة ربط مدن الدولة اقتصادياً.

$$
\begin{aligned}
& \text { 30 } 30 \\
& 31 \\
& 32 \\
& 33 \\
& 34
\end{aligned}
$$

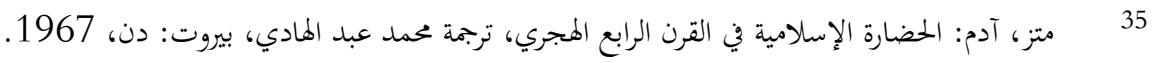


ولسبق العراق غيره إلى المعاملات المصرفية نرى ارتباطاً وثيقاً بين الحجاز ومصر والشام والأندلس بالمؤسسات المصرفية العراقية، 36 وكان للمنافسة بين العباسيين في بغداد والفاطميين في مصر وشمال إفريقيا دورٌ حيث شجع الفاطميون انتقال أرباب رؤوس الأموال إلى مصر، وكان بينهم عدد من الصيارفة العراقيين وسَهَّل انتقالهم وجود فروع، مصرفية في صر للمصارف العراقية. 37

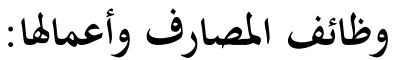

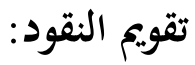

وهي مهمة ذات أهمية كبيرة يقوم بها الصيرفي قبل أن ينجز أية معاملة مالية، فيعمد أولاً إلى تقدير قيمة النقد الشرائية وتسمى هذه العملية عند بعضهم بالنقاد، 38 من نقد الدرهم وهو التمييز بين جيدها ورديئها، وكما قلنا فهي عملة مهمة وشاقة في الوقت نفسه ولكن لكثرة المعاملة المصرفية أصبح لدى الصيارفة خبرة في اختبار النقود واتبعوا في ذلك وسائل متعددة بسيطة وأخرى معقدة تبعاً لنوعية النقود ونوعية الغش والتدليس المستخدمة فيه. 39 وتتضح أهمية الصرافين أكثر إذا علمنا أفم الجهة الوحيدة التي تتولى تقويم النقود ومدى جودما وزغها وقيمتها بين النقود المتداولة. 40

ومن الطرائق المستخدمة من قبل الصيارفة في اختيار النقود وتقويم قيمتها النقدية:

1-الاعتماد على ثقل الدينار وصوته" فإن للذهب من الثقل وتلزّم الأجزاء صفة لا يدانيها فيها ما يغش به، وكذلك صوته إذا نقر فإنه رخيم معتدل فإذا غش بالنحاس أو الفضة ظهر في صوته دقة واحدة تدل على صلابة وصلت في مجلسه. 41

2-يوضع الدينار بين الأسنان فإذا كان ليناً دل على جودته أما إذا كان صلباً كان رديئاً. 42

$$
\begin{aligned}
& 36 \text { 36 الكبيسي، جمدان: المؤسسات الاقتصادية، محاضرات كلية الآداب، قسم التاريخ، } 1988 . \\
& 37 \\
& 38 \text { لسعدي، أمل: الصيرفة والمهبذة في العراق، رسالة دكتوراه غير مطبوعة، كلية الآداب، امعة بغداد، 1985، ص } 102 . \\
& 39 \\
& \text { 40 } 40 \\
& 41
\end{aligned}
$$


3-الاعتماد على حمي الدينار بالنار فإذا اسوَّد أو اخضرَّ كان مغشوشاً. 43

4-التعليق، وهي من أكثر الطرق سلامة وهي أن يدق الذهب بعد إضافة الملح فإن تغير لونه شُك

في نقاوة الدينار.

5-وهناك طريقة بسيطة أوردها الجاحظ وهي أن يقرب الدينار من الشعر ويلاحظ مدى التصاق

الدينار وصعوبة استمراره فإذا كان جيداً صَعُبَ استمرار التصاقه. 45

6-استعمال محاك المنتقد، 46 الذي يختبر به جودة القطع النقدية.

7-يقوم الصيرفي بكسر الدينار، 47 وملاحظة غشه أو قطعه بالكار وملاحظة التدليس والغش الموجود

أما بالنسبة إلى تقويم الدراهم واختبارها فهناك طرق كثيرة وعديدة لكشف زيف الدرهم ومدى نقاوته

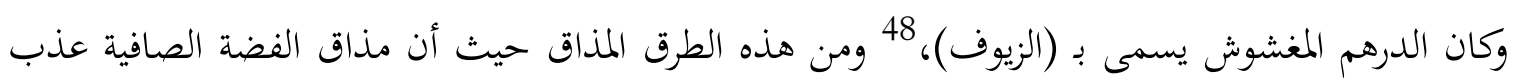
ومذاق المغشوش مر، 49 وكذلك بواسطة كسر الدرهم الذي شك بصحته وملاحظة غشه، وهناك طريقة الحمي أيضاً فإذا اسودَّ الدرهم كان مغشوشاً، وطريقة سبك الروباس، 50 وأيضاً طريقة قياس الوزن للقطع النقدية في المواء والماء ثم تُقارن النسبة. 51

ب) تحويل العملات النقدية وصرف الصكوك والسفاتج:

$$
\begin{aligned}
& 42 \\
& \text { 4 الدمشقي، ص } 73 \\
& 44 \text { الجاحظ، عمرو: التبصرة بالتارة، تعليق حسن عبد الوهاب، القاهرة: المطبعة الرمانية، 1935، ط } 2 \text { ص } 11 . \\
& 45
\end{aligned}
$$

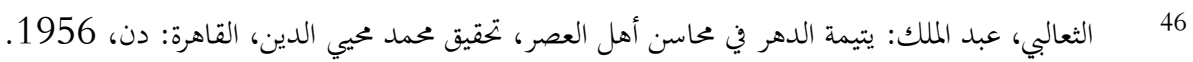

$$
\begin{aligned}
& \text { الد } 47
\end{aligned}
$$

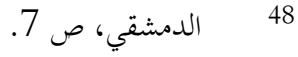

$$
\begin{aligned}
& \text { 4 } 49 \\
& 50 \\
& 51
\end{aligned}
$$


يقوم الصيارفة بعمل مهم وهو أساسُ وجوهري بالنسبة للتعامل المالي حيث كانوا بمثابة العمود الفقري للأسواق بما يقدمونه من خدمات كبيرة للتجار، فهم الذين يتحملون مسئولية تبديل العملات النقدية وتحويلها من فئة إلى أخرى ويقومون أيضاً بصرف الصكوك والسفاتج.

وكان دور الصيارفة أوضح في أسواق المدن التي توجد فيها مختلف العملات النقدية حيث يُعدم التعاملُ النقديٌُ في مثل هذه الأسواق في حالة عدم وجود الصيارفة، ويكون تبديل العملات المتداولة في الأسواق التجارية إما بتحويل العملات الأجنبية إلى العملات المتداولة في الدولة العربية الإسلامية أو بتحويل الدراهم إلى الدينار وحسب ضرورة التعامل المالي.

ولعبت عدة عوامل في إكثار تدفق العملات الخارجية إلى الدولة العربية الإسلامية، منها الجبايات التي ترسل من الأقاليم إلى الدولة فهناك الدراهم القطريفية والخمدية والخوارزمية والمسيبية، 52 وتصرف هذه القيم النقدية من قبل صيارفة الدولة في الأسواق (الجهابذة) أو عند المصرفيين الموجودين في الأسواق، ومن العوامل الأخرى ما يرد به التجار من الخارج من عمل نقدية غير متداولة في الأسواق المحلية.53 53

وكانت قيمة النقود متذبذبة في أسواق التعامل المالي، فتارة يصل الدينار إلى عشرة دراهم، وتارة يصل إلى ثلاثمائة درهم، 54 وكان تدفق معدني الذهب والفضة له أثر في زيادة أسعار العمل النقدية والخفاضها فعرقلة الطرق وسوء العلاقات السياسية يؤدي إلى انقطاع تدفق هذا المعدن أو ذاك فيؤدي إلى تغيير نسبة التبادل فيها.

ولا يُخفى أن القدرة الشرائية للنقد تعتمد على قوة اقتصاد الدولة الإسلامية وعلاقتها المالية مع البلدان الأخرى، 55 ويرى البعض أن هناك علاقة وطيدة بين الكمية المضروبة في دور الضرب وأسعار تبادل الدنانير

$$
\begin{aligned}
& 52 \\
& 53 \text { المقدسي، محمد: أحسن التقاسيم في معرفة الأقاليم، بيروت: دن، 1909، ط 2، ص } 239 . \\
& 54 \\
& 55
\end{aligned}
$$


والدراهم، 56 وكان لتدخل الدول وتحديد أسعار التبادل أثر في قيمة النقود. كما حصل في القرن الرابع الهجري عام 389هـ حين قررت الدولة سعر الدينار بثلاثمائة درهم.

\section{أهم المعاملات التي يقوم بما الصيارفة:}

وهي عملية بيع الذهب بالذهب والفضة بالفضة بمثله وزنا ويكون ذلك بوضع الذهبين في كفتي الميزان فإذا استوت الكفتان كان ذلك الوجه الصحيح للمعاملة، 57 استناداً إلى الحديث الشريف"الذهب بالذهب ربا إلا هاء وهاء"، 58 وقال أيضاً"لاتبيعوا بالذهب إلاعينا بعين ولا الورق بالورق إلاعيناً بعين، إني أخشى عليكم الرماء ولا تبيعوا الذهب بالورق إلا هاء وهلم ولا الورق بالذهب إلا هاء وهلم". 59 روى أبو هريرة عن النبي صلى الله عليه وسلم أنه قال:"الذهب بالذهب وزناً بوزن مثلاً بمثل. الفضة بالفضة وزناً بوزن مثلاً بمثل فمن زاد أو استزاد فهو ربا". 60

وعن سعد بن عبادة"كنا نبايع اليهود عام خيبر الأوقية من الذهب بالدينارين والثلاثة فنادى رسول

$$
\text { الله لا يحل الذهب إلا وزنا بوزن". } 61
$$

وعن أبي سعيد الخندري عن النبي صلى الله عليه وسلم قال:"الذهب بالذهب والفضة بالفضة والبر بالبر والشعير بالشعير والتمر بالتمر مثلاً بمثل يداً بيد فمن زاد أو استزاد فقد أربى الآخذ والمعطي فيه سواء". 62 وهناك شروط وضعها الفقهاء في صحة عملية المراطلة وهي تَسَاوي وزن القيمتين وكذلك المساواة

$$
\begin{aligned}
& 56 \text { } 57 \text { الصيرفة، السعدي، ص } 127 . \\
& 57 \\
& 58 \text { ( المرجع السابق، ص } 57 \\
& \text { (5) } 59 \\
& 60 \\
& 61 \\
& 62 \text { } 61 \text { المرجع السابق، ج } 11 \text { ص 11، ص } 14 .
\end{aligned}
$$


في جودة النقد المراطل به، ولا يجوز أن يقترن مع المراطلة عقد بيع، قال مالك فمن أتي بذهب هاشمية إلى صراف فقال له راطلني بها بذهب عتيق هي أكثر عدداً من عددها وانقص وزناً من الهاشمية، فكان إنما أعطاه فضل عيون القاتمة الهاشمية بمكان عدد العتيق وفضل عيوها. 63

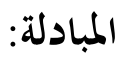

وهي عملية بيع النقد بمثله، 64 والمعاملة بالمبادلة تكون قليلة ومحدودة لأها عددت فقط بالمعدود من الدراهم والدنانير وهو في العدد جائز عند مالك فيما قل مثل الدينارين والثلاثة والدرهمين والثلاثة إذا استوى العددان فإن كثر العدد لم يصلح، 65 ووضع الفقهاء ضوابط لهذا النوع من المعاملات النقدية وفي المبادلة أن تتم المعاملة يداً بيد لا يفارق أحدهم الآخر قبل أن يتم قبض المبلغين وأن بتري المبادلة دون شروط مسبقة.

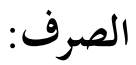

وهي عملية بيع الفضة بالذهب، 67 وهناك ضوابط فقهية حددت سلامة هذه المعاملة المالية منها أن تذكر حصة كل دينار وعملة الصرف، فتقول أبيعك هذه العشرة دنانير كل دينار بعشرة دراهم، وعقد المصارفة يجب أن يتم حالاً وفي المجلس، وكل أمر يؤخر عملية التقابض هذه من شأنه أن يبطل البيع لقول الرسول صلى الله عليه وسلم: "لاتبيعوا منها غائباً بناجز". 68 بالإضافة إلى تحويل العملات النقدية كان يقوم الصيرفي بتصريف الصكوك والسفاتج وبذلك ساعد على إحداث السيولة النقدية وسمح بانتقال الأموال وحافظ عليها من الضياع والسرقة. والصكوك وسيلة من وسائل الائتمان وهو أمر خطي بدفع مقدار من النقود إلى الشخص المسمى فيه، 69 وكان الصك يستعمل على الصعيدين الرسمي والشعبي وكانت الرسمية منها

$$
\begin{aligned}
& 63 \\
& 64 \\
& 65 \\
& 66 \\
& 67 \text { } 67 \\
& 68 \text { 6 } 68 \\
& 6969
\end{aligned}
$$


تستخدم لدفع الرواتب وأززاق الجند وقد استخدم عمر بن الخطاب الصك وختم أسفله، 70 وكانت بعض الصكوك الحكومية تصرف في بيت المال، وقد يؤجل صرف الصك لعدم توفر المال الكافي فقد امتنع صاحب الديوان صرف صك يزيد بن المهلب قائلاً له: "إن خراجك لا يفئ به الخراج"، 71 وقد تصرف هذه الصكوك عند الصيارفة وكان حاصل الصيري درهاً في كل دينار في بعض الأحيان بمثابة رسم على صرف الصكوك، وكان الصك يقوم مقام سند الدين على الأشخاص إذ أورد الصابي أن الوزير علي بن الفرات يصك لشخص آخر، وقال هذا صك عليّ بن فرات بثلاثة آلاف درهم فيجعلها بنفقنه. 72 وشاع استعمال السفتجة في الدولة الإسلامية وهي من وسائل الائتمان أيضاً ويقصد بها الحوالات أو ورقة مالية أو خطاب ضمان ويعني: "أن يعطي رجل مالاً لآخر وللآخر مالٌ في بلد المعطي... فيوفيه إياه

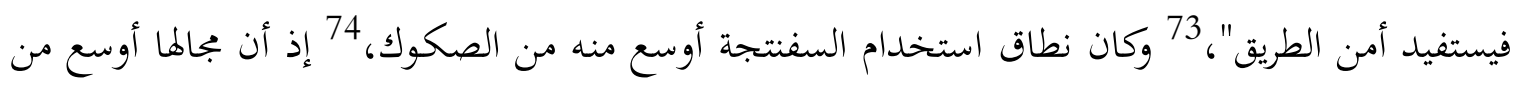
البلد الواحد الذي غالباً ما كانت تتم فيه الصكوك، أما السفاتج فتنظم مثلاً من قبل أحد صيارفة العراق ويحولها إلى أي جهة مالية معروفة، وكان لها دور في توثيق العلاقات بين المؤسسات المصرفية في أقاليم الدولة الإسلامية، وتعتبر السفنتجة من أرقى أنواع التعامل المالي المصرفي وهي تشبه إلى حد كبير شكل الحوالة التجارية أو ما يسمى بالكمبيالة. 75

وكان مصدر الصيارفة لقاء هذه الخدمات الواسعة أرباح طائلة فيذكر"أن رجلا كتب إلى مغن رقعة إلى صراف يعامله بخمسمائة دينار فذهب المغني إلى الصيرفي وأعطاه الرقعة فسأله الصيرفي: أنت الرجل المسمى في التوقيع؟، قال: عم، فقال الصيرفي: أنت تعلم أمثالنا يعاملون للفائدة وربحنا أن يعطي في كل وكان مصدر الصيارفة لقاء هذه الخدمات الواسعة أرباحُ طائلة فيذكر"أن رجلاً كتب إلى مغنِّ رقعة إلى صراف يعامله بخمسمائة دينار فذهب المغني إلى الصيرفي وأعطاه الرقعة فسأله الصيرفي: أنت الرجل المسمى

$$
\begin{aligned}
& 70 \\
& 71
\end{aligned}
$$

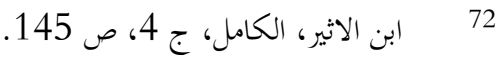

$$
\begin{aligned}
& 7374 \\
& \text { 74 } 74 \\
& 75
\end{aligned}
$$


في التوقيع؟، قال: نعم، فقال الصيرفي: أنت تعلم أمثالنا يعاملون للفائدة وربجنا أن يعطي في كل دينار درهم، 76 وكذلك قام الصيارفة بالتوسط بين الناس ودور الضرب فكانوا يأخذون الذهب والفضة من الناس لسكها ثم يدفعون لم نقوداً تعادلها في القيمة الاسمية وبذلك يستفيدون من الفرق بين القيمتين. 77

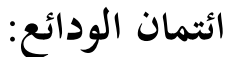

ومن الوظائف الأساسية التي كانت تقوم بها المصارف هي قبول الودائع وائتمان الأموال، ويُذكر إن استوداع الأمانات كان شائعاً منذ صدر الإسلام فيروي ابن سعد عن ودائع الزبير ابن العوام التي بلغت مليونين ومائتي ألف درهم حيث يقول: "الرجل كان يأتيه بالمال ليستودعه إياه فيقول الزبير: لا، ولكن هي سلف إني أخشى عليه الضيعة"78 وكان الصرافون يقبلون الودائع ويعملون على تسهيل عمليات الائتمان وبخاصة في البصرة فقد ذكر ناصر خسروا إن المعاملات التجارية فيها بتري كما يلي" كان كل من لديه مال يعطيه للصراف ويأخذ منه صكاً ثم يشتري به ما يلزمه أو يحول الثمن على الصراف وبذلك لا يستخدم المشتري شيئاً أثناء إقامته بالمدينة سوى صك الصراف، 79 وقد توسعت عمليات الصرف هذه بتوسع النشاط التجاري والزراعي وزيادة دخل الفرد فكان الصرافون يقبلون أحياناً الودائع من الموسرين، 80 ويذكر أغم كانوا يتقبلون ائتمان مختلف الودائع النقدية والعينية وقطع المجوهرات والمعادن الثمينة. 81

وكانت تمثل هذه الودائع المصدر الأول لأموال الصرافين، 82 فيما رأى البعض، 83 ضرورة عدم المبالغة في أهمية الودائع في تكوين رؤوس أموال الصرافين لأن أغلب الناس كانوا يميلون إلى خزن ثرواتم وبتميدها، ولكن فيما يبدو ومن خلال استعراض ائتمان الأموال وملاحظة كثرةا إنما كانت تشكل مصدراً مهماً من

$$
\begin{aligned}
& 76 \text { 7 الكبيسي وآخرون: العراق في مواكب الخضارة، بغداد 1988، ج 2، ص } 161 . \\
& 77 \\
& 7878
\end{aligned}
$$

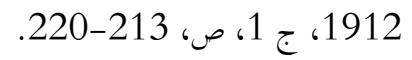

$$
\begin{aligned}
& 79 \text { ابن الأخوة، معالم القربة، ص ص } 68 \text {-الدوري: تاريخ العراق، ص } 170 . \\
& 80 \\
& 81 \\
& 82 \\
& 83
\end{aligned}
$$


مصادر أموال الصرافين، فقد ذكر أن أبا علي خازن معز الدولة كانت له مبالغ ضخمة عام (359هـ 961م) فكان مجموعها مائتي ألف دينار منها خمسون ألف عند أحد الصيارفة في درب العيون في بغداد، 84 وربح أيضاً في خلافة المقتدر (320-295هـ) من ضمان بعض الضياع عشرة آلاف دينار قام بإيداعها عند أحد الصيارفة، 85 وكان لدى أحد بتحار بغداد عشرة آلاف دينار موزعة عند عدد من الصيارفة. 86

وجاء عن أبي العلان الأهوازي الكاتب:" نظرت في الضمان وتصرمت السنة فربحت عشرة آلاف دينار . . . فأثبتها عند الصارفه8 87، فيبدو أن عملية الائتمان كانت موجودة وبمبالغ ضخمة فكانت تشكل مورداً يمول رأسمال الصرافين. وكان الصرافون يتحملون مسئوليات وواجبات بتحاه الودائع فكانوا يعملون جادين في سبيل الحفاظ على الأموال المودعة ويتخذون الوسائل كافة للحفاظ على الأمانات، وزيادة في الحفاظ والضمان كان عند المصرفيين سجلٌ خاصٌ يدون فيه أسماء الأشخاص المودعين أموالهم وقيمة ودائعهم، وكان بالمقابل عند بعض أصحاب الودائع مثل هذا السجل حفظاً لسلامة أمواهم المودعة خصوصاً إذا كانت موزعة عند عدد من الصيارفة، 88 وهناك سجل يثبت هذه الأموال برموز فأورد التنوخي عن ابن أبي علان الأهوازي قال" سلمت إليه رقاع الصيارف بالمال وأخذت منه حجة بإزالة المطالبة وانصرفت. 89

تعدّ الأموال المودعة خير معين للصيارفة في تسيير معاملاتم المالية إذ تيئ لهم سيولة نقدية تمكنهم من إعطاء القروض، وتضع بأيديهم فئات متعددة من العملات التي جاءقم من ودائع التجار الأجانب، فهي توفر للصيرفي فرصة باستثمارها في مشاريع اقتصادية مثل الدخول في المضاربات وتأسيس الشركات، 90 ويذكر أن سحب الودائع كان بواسطة صكوك تنظم لهذا الغرض. 91

\begin{tabular}{|c|c|}
\hline الدوري: تاريخ، ص 172. & 84 \\
\hline العلي: تنظيمات، ص 260. & 85 \\
\hline مسكوية: بحارب، ج 2 ص 188. & 86 \\
\hline التنوخي: النشوار، ج 1 ص 214. & 87 \\
\hline المرجع السابق، ص 79. & 88 \\
\hline المرجع السابق، ج 1، ص 214. & 89 \\
\hline السعددي: الصيرفة، ص 140. & 90 \\
\hline التنوخي: النشوار، ج 8، ص 271. & \\
\hline
\end{tabular}




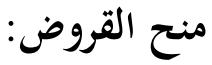

كانت من الأعمال التي يقوم بها الصيارفة منح القروض للمحتاجين والتجار الذين يلجأون إليهم في تسيير معاملاكم التجارية، ووردت عدة أخبار عن وجود مثل هذه المعاملات لاسيما إقراض التجار، فكان على أبي بكر بن جعفر أحد بحار الكرخ ببغداد قسطٌ يدفعه إلى ابن عيدان الصيرفي من مشاهير صرافي درب عون فأخَّر دفع المبلغ لضرورة ألَّمت بالتاجر، 92 وجاء عن أبي العلان الأهوازي قال"انفذت إلى وكلائي في

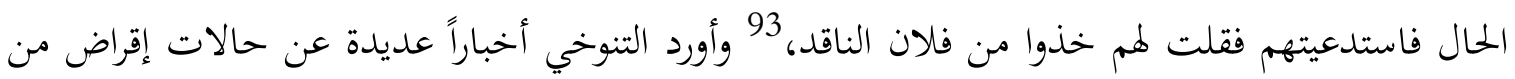
الصيارفة إلى أناس عاديين غير بحار فعن طالوت بن عباد الصيرفي قال: "كنت بالبصرة. . فإذا ابن الخياطة ينبهني من فراشي. . فقال قمرت الساعة خمسمائة دينار أقرضني إياها. . فأخرجت خمسمائة دينار فدفعتها إليه"،94 وجاء في المنتظم"خرج أبو عبد الله بن أبي بكر الآدمي القاري من مترله وأخذ من بعض الصيارف

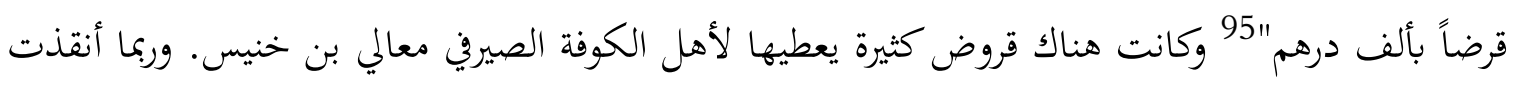
هذه القروض بعض الناس من مأزق، أورد ابن بطوطة عن رجل من أهل الشام أنه:"أخذ مرة من بعض تحار

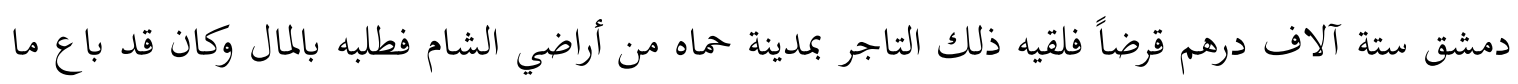
اشترى به من المتاع بالدين فاستحيا من صاحب المال ودخل إلى بيته وربط عمامته بسقف وأراد أن يخنق نفسه وكان في أجله تأخير فتذكر صاحباً له من الصيارفة فقصده وذكر له القضية فسلفه مالاً ودفعه للتناجر .

ولم تقتصر القروض على التجار وعامة الناس وإنما ورد عن بعض الخلفاء والمسئولين في الدولة أفم اقترضوا مبالغ احتاجوها، "لما ولي الحلافة أبو العباس السفاح قدم عليه بنو الحسن بن علي أبي طالب فأعطوهم الأموال وقطع لهم القطائع. . . فاستقرضهم أبو العباس من أبي مقرن الصيرفي وأمر له بها "، 97

$$
\begin{aligned}
& 92 \\
& 93 \\
& 94 \\
& 95
\end{aligned}
$$

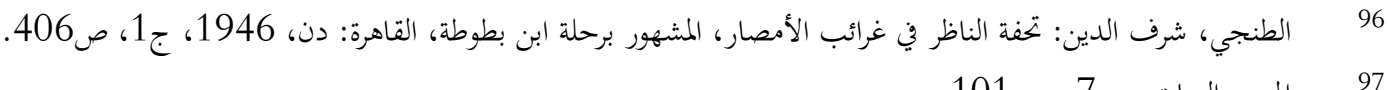

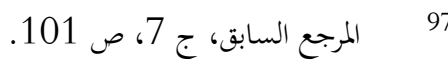


وكذلك استعانت الدولة بالصيارفة في تمويل مشاريع عمرانية" عقد المنصور عند باب الشعير وجرى ذلك على يد حميد القاسم الصيرفي" "98 ولكن يبدو إن القروض التي كان يقدمها الصيارفة كانت إلى التجار أكثر منها من عامة الناس وبدرجة أقل إلى الدولة العربية الإسلامية.

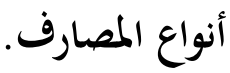

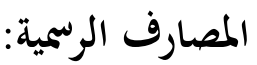

كان بيت المال في الدولة الإسلامية مؤسسة اقتصادية كبيرة تقوم بمهام مصرفية كبيرة ذات مردود إيجابي على عامة أبناء المجتمع باعتباره ملكاً للأمة. وقد تنوعت المهام المصرفية التي قام هما بيت مال المسلمين بحسب التطورات والمستجدات الاجتماعية والاقتصادية وأحياناً بحسب الظروف الطارئة فكان بيت المال بمثابة مصرف رسمي عام يؤدي عدة مهام في آن واحد فهو أحياناً يقدم سلفة مستعجلة لمعالجة بعض الأوضاع الطارئة وتتوقف قيمة السلفة ومقدارها بحسب حالة السيولة في بيت المال وتقدير القائمين على الدولة الإسلامية لأهمية هذا الأمر دون غيره وفي كثير من الحالات يقدم سلفاً وقروضاً مستعجلة لإنعاش أوضاع المزارعين فقد أقرض الحجاج بن يوسف الثقفي الفلاحين في العراق مليوني درهم من بيت مال واسط، 99 وكذلك فعل الخليفة عمر بن عبد العزيز (99هـ-101هـ) عندما أقرض فلاحي العراق لتحسين

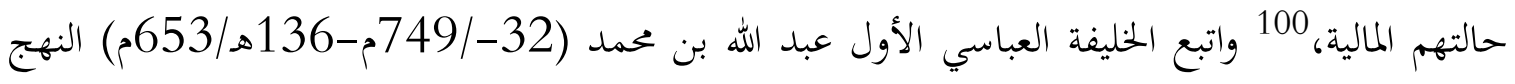
نفسه بتحاه الفلاحين فاسقط في إحدى السنوات الخراج عن بعض المزارعين وأقرضهم مائتي ألف درهم لسوء موسمهم الزراعي، 101 وأقدم الخليفة المتوكل (232هـ/846م-247هـ/861م) على تسليف الفلاحين في منطقة باسورين مبلغاً مقداره عشرة آلاف دينار لمواجهتهم فاقة بسبب هطول الثلوج، 102 وقدمت عشرة

$$
\begin{aligned}
& 989
\end{aligned}
$$

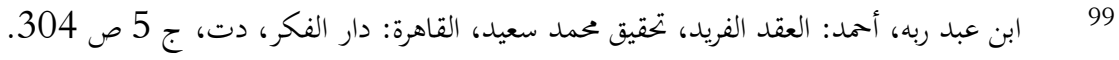

$$
\begin{aligned}
& 100101 \\
& 101102 \\
& 102
\end{aligned}
$$


آلاف دينار أخرى في خلافة المعتضد (279هـ /892م-289ه/901م) لفلاحي الصلح والمبارك في المنطقة الممتدة بين واسط والبصرة، 103 وعمل كل ذلك على رفع مستوى الإنتاج الزراعي.

أما أساليب تسديد السلف الزراعي فكانت متباينة، فالحجاج أضاف القرض إلى الخراج في جبايته، 104 وفي زمن السفاح كانت مدة السلف سنة واحدة، 105 وبعضهم استرجع القرض بعد شهور، 106 ومنهم من أخَّره، ومنهم من أخره إلى وقت الحصاد. 107

فضلاً عن القروض والسلف الزراعية كان يقوم بيت المال بعمليات التمويل للتجار تشجيعاً لهم، فأقرض عمر بن الخطاب (هنداً بنت عتبة من بيت المال سلفاً مقداره أربعة آلاف درهم تتاجر فيها)، 108 وكذلك اقترض عبيد الله بن عمر من بيت مال البصرة أيام أبي موسى الأشعري مالاً اشترى به بضاعة أخذها إلى الحجاج فكان بيت المال للمتاجرة ثم دفع ما اقترضه إلى بيت مال الحجاج فكان بيت المال يقوم بدور المقاصة لتسهيل المعاملات التجارية. 109

وكان بيت المال يقدم القروض العقارية لغرض البناء وإقامة العمران؛ فأورد مسكويه إلزام مسئولي الدولة أصحاب العقارات التي تضررت لتمادي الزمن عليها أو لتضررها نتيجة الفتن أو الظروف الطبيعية المختلفة، فألزموا بضرورة إعادة تعميرها، ومن لم يستطع اقتراض من بيت المال ليربح منه عند الميسرة... ومن لمم يوثق منه بذلك أو كان غائباً أقيم عنه وكيل. 110

$$
\begin{aligned}
& 103 \text { 104 الأعظمي، عواد: دراسات في تاريخ الاقتصاد العربي والإسلامي، بغداد: مطبعة التعليم العالي، 1988، ص199. } \\
& 104 \\
& 105 \\
& 106 \\
& 107 \\
& 108 \\
& 109 \\
& 110
\end{aligned}
$$


فضلاً عن القروض المذكورة التي يقدمها بيت المال كان يقوم بتقديم قروض شخصية، فقد اقترض الخليفة أبو بكر الصديق (11هـ/623م-13هـ/634م) من بيت المال"إٕي استلفت من بيت مال المسلمين مالاً فإذا مت فليبع حائطي وليرد إلى بيت المال. 111 وكذلك فعل الخليفة عمر بن الخطاب (13هـ/634م-22هـ/642م) "إني استلفت من بيت مال المسلمين ثمانين ألفاً فليرد من مال ولدي"، 112 وكان هذا بعد أن طُعن عمر، وكانت هناك قروض كثيرة لأشخاص معروفين فكان يقدم بيت المال المبالغ التي يطلبوها، فقد أقترض سعد بن أبي وقاص مبلغاً من المال في خلافة عثمان بن عفان، 113 واستلف المهلب بن أبي صفرة مبلغاً قدره ثلاثمائة ألف دينار من بيت المال، 114 واقترض الجراح بن عبد الله من بيت المال عشرة آلاف درهم في عهد الخليفة عمر بن عبد العزيز. 115 ولم تقتصر القروض على الأشخاص المعروفين بل شمل عامة الناس، فقد أقرض بيت المال الجند كما حدث في خلافة المأمون، كما حصلت قروض مختلفة للكتاب والعمال، 116 وكانت تسترد هذه القروض من آخذيها أو وكلائهم أو بعد بيع عقاراتم. ومن الأعمال الأخرى التي كان يقوم بها بيت المال التعامل بالنقد فقد كان يبيع النقود الزائفة

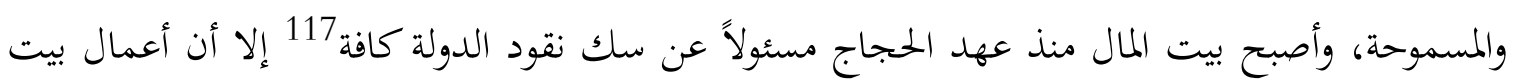
المال المذكورة لم تمنع المسئولين في الدولة العربية الإسلامية من تأسيس مصارف حكومية تقوم بمهام ذات قيمة كبيرة للدولة وقت الرخاء الاقتصادي ولحل الأزمات الاقتصادية وقت حدوثها، فقد أسس الوزير علي بن عيسى مصرفاً رممياً لمواجهة أزمة مالية حدثت في سنة 300هـ فاستدعى صرَّافِيْن من أهل الذهة، 118 وكانا ثريين وطلب منهما تأسيس مصرف رسمي مهمته تسليف الدولة ما تحتاج من نقود معتمدين على واردات

$$
\begin{aligned}
& 111 \\
& 112 \\
& 113 \\
& \text { (السعدي، الصيرفة: ص } 243 . \\
& 115 \\
& 116 \\
& 117 \\
& 118 \text { الوزراء، هما يوسف بن فنخاص، وهارون بن عمران، راجع الصابي، الوزراء: ص 90. والتنوخي النشوار: ج8، ص } 41 .
\end{aligned}
$$


الأهواز كضمان لمما "قال علي بن عيسى إني أحتاج في كل هلال إلى مال أدفعه. . . وأريد أن تسلفاني في أول كل شهر مائة وخمسين ألف درهم تربتعاها من مال الأهواز في مدة الشهر، فإن جهبذة الأهواز إليكما فيكون هذا المال سلفاً لكما". وبقي هذا المصرف يقوم بمهمته طوال ست عشرة سنة. 119

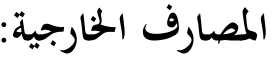

كان أصحاب المصارف هم الأشخاص الذين يملكون أموالاً طائلة يوظفوها في الأعمال المالية والإقراض، وكانوا في الوقت نفسه يمارسون التجارة وغيرها من الأعمال الاقتصادية، وكانوا يستفيدون من الودائع التي يأخذوغا عندهم ويستثمروها في الأعمال المالية، فورد أن الزبير بن العوام كان لديه ما يشبه البنك

$$
\text { إذ معظم أمواله من الودائع. } 120
$$

وكان أغلب الصيارفة هم نصارى انتقلوا من الكوفة بعد فتحها إلى المدن الأخرى خاصة بغداد والبصرة وساهموا مساهمة فعالة في الأعمال المصرفية، 121 فورد عن الجاحظ"ما عظم النصارى في قلوب العوام أن منهم

$$
\text { كتاب السلاطين.... وأطباء الأشراف... والصيارفة. } 122
$$

وزاحم النصارى في الصيرفة اليهود، قال المقدسي وهو يتكم عن إقليم الشام:"وأكثر الجهابذة

$$
\text { والصباغين والصيارفة هذا الإقليم يهود. } 123
$$

وأكد آدم متز، صاحب كتاب الحضارة في القرن الرابع الهجري، أن حرفة اليهود في الشرق هي الاتحار بالعملة، وكان ثلاثة جهابذة يهود في الدولة العربية الإسلامية في القرن الرابع الهجري يسمون جهابذة الحضرة لارتباط عملهم مع مسئولي الدولة، فكان نشاط النصارى واليهود ملحوظاً في الدولة مما يدل على روح

119 الأنصاري، أحلام: التطور التجاري والنقدي في العراق، رسالة ماجستير، كلية الإدارة والاقتصاد، جامعة بغداد ص133.

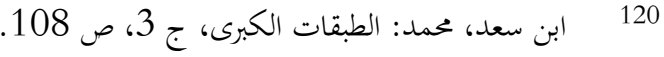

$$
\begin{aligned}
& 121 \\
& 122
\end{aligned}
$$

123 
التسامح السائدة في الدولة العربية الإسلامية، وكان للمسلمين دور كبير في الصيرفة ولخشية التعامل بالربا عمد المسلمون إلى الجمع بين التجارة والصيرفة. 124

وكان للصرافين وجود في معظم أسواق المدن مثل بغداد والبصرة والكوفة والقيروان والفسطاط وأصفهان وغيرها، وكان للصرافين أسواق خاصة بكم مثل سويق درب عون ببغداد، 125 وسوق الصرافين في اصفهان 126 كل ذلك يدلّ على أهمية الصراف بالنسبة للتعامل الاقتصادي في الدولة.

وكان لبعض المصارف الخاصة فروع في الأقاليم حيث ورد أن مصرف الزبير بن العوام كان مركزه المدينة

وله فروع في الكوفة والبصرة، 127 وكانت هذه المصارف قريبة الشبه بالبنوك الحديثة من حيث تعاملهم فهي تقوم بالإقراض والتسليف وكذلك يتقبلون الودائع من الناس، وكانوا يقومون بدور الوسيط بين الناس ودور الضرب، حيث يأخذون الذهب والفضة من الناس لسكها ثم يدفعون لهم نقوداً تعادلها في القيمة، 128 وكان التجار هم أكثر المتعاملين مع الصيارفة، بل كان أهل المصارف يساهمون في شركات بتحارية تضامنية مع عدد من التجار.

ويمكن القول أن الصيارفة قدموا خدمات كبيرة للتجار فكانوا خير مساعد ومشجع لنشاطهم التجاري، من حيث التصريف النقدي والتسليف والقروض، بل كان وجودهم حفظاً لأموال التجار وماية لمعاملتهم النقدية من خلال استعمالمم السفاتج والصكوك فسهلوا بذلك التبادل التجاري بين أقاليم الدولة الإسلامية.

وكذلك كان للمصارف الخاصة تعامل مع الدولة فساهم الصيارفة أحياناً في حل الأزمات المالية التي تمر بها الدولة، فأورد الطبري 130 أن أحد الصيارفة ساهم بمشاريع عمرانية في سنة 157هـ في خلافة المنصور،

$$
\begin{aligned}
& 124 \\
& 125 \\
& 126
\end{aligned}
$$

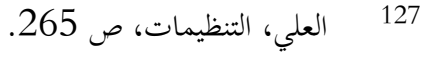

$$
\begin{aligned}
& 128 \text { الدوري، تاريخ: ص } 170 . \\
& 129 \\
& 1300
\end{aligned}
$$


وكذلك اقترض السفاح من الصراف أبي مقرن ألف درهم لسد حاجة الدولة المالية، 131 واستعان علي بن الفرات بصرافين من أهل الذمة سنة 296هـ محاولة لحل أزمة مالية، 132 واستعان الوزير علي بن عيسى بيوسف بن فنخاص وهارون بن عمران الصرافين، 133 وكذلك اقترض الوزير عبد الله بن محمد الكلوذاين عام إمرام 318هـ من أبي بكر بن؟ قرابة مائتي ألف دينار بربح درهم في كل دينار، 134 واقترض أيضا الوزير الحسين

$$
\text { بن قاسم من الصراف المذكور. } 135
$$

واهتمت الدولة الإسلامية بشؤون الناس ومصالحهم فأولت الصيارفة وأعمالهم أهمية بالغة نظراً للدور المهم الذي يلعبه هؤلاء في الأسواق والمعاملات المالية فجعلتهم تحت عين المراقبة ووضعت الضوابط لأعمالهم وفرضت العقوبات على المخالفين منهم، وكذلك وضح الفقهاء ضوابط محددة لعمل الصيارفة خشية وقوعهم في الربا، فكانت حسبة على الصيارفة حيث كان يراقب عملهم خشية ترويمهم العملة المزيفة ومراقبة موازينهم ومنع تعاملهم بالربا، وأوكلت للمحتسب مهمة متابعة أسواق الصيارفة للوقوف على المعاملات الجارية فيها، 136 وأصدرت الدولة عقوبات على المخالفين تراوحت بين الحبس والتعزير، 137 ولم تقتصر عملية المراقبة على الختسب بل تعدها إلى الأمراء فورد عن ناصر الدولة أنه بلغه أن الصيارفة يربون رباء ظاهراً فأحضرهم

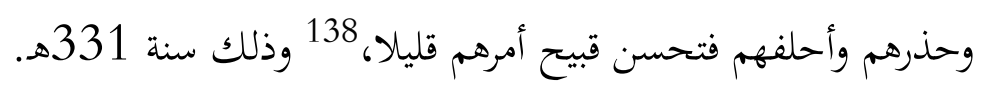

وأخيراً يمكن القول بأن المصارف الخاصة لعبت دوراً مهماً في التعامل المالي وتشجيع المعاملات الاقتصادية وتسهيلها، وكانت تعتمد على شخصية مالكها فإن مات انحلت بعد موته. 139 وترى من خلال الأعمال والوظائف التي كانت تقوم بها المصارف الخاصة أها أشبه بالبنوك الحديثة.

$$
\begin{aligned}
& 131 \text { ابن عبد ربه، العقد الفريد: ج 5، ص } 332 . \\
& 132 \\
& 133 \\
& 134 \\
& 135
\end{aligned}
$$

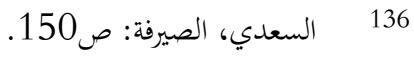

$$
\begin{aligned}
& 137
\end{aligned}
$$

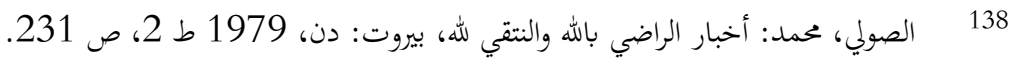

$$
\begin{aligned}
& 139
\end{aligned}
$$


لعبت المصارف دوراً كبيراً في زيادة نشاط اقتصاد الدولة العربية الإسلامية، فكان لها الفضل الأول في إدامة حيوية أسواق الدولة واستمرار التعامل التجاري بين أطراف الدولة والمركز.

فالقروض التي قدمها الصيارفة للتجار ساعدقم على القيام بمهامها التجارية وتوسيعها وأبقت على قوة التعامل التجاري، فساهمت إلى حد ما في ازدهار الأسواق وانتعاشها، ثم بعملية الائتمان حفظت الأموال من الضياع وأبعدت عنها أيدي اللصوص. ومن جهة أخرى استثمرت هذه الودائع بإقامة المشاريع التجارية فجنبّت الدولة بذلك من الوقوع في أزمات اقتصادية وساعدها بالوقوف على أقدامها في مواقف عديدة.

وكان تصريفها للعملات عملاً شجع التجار الأجانب على دخول الأسواق التجارية في الدولة الإسلامية واستمرار تعاملهم التجاري مع الأسواق الإسلامية.

ومما زاد في تقدم خدمات الصيارفة في الميدان الاقتصادي أفم كانوا أنفسهم مشتغلين بالعمل التجاري

$$
\text { ومؤسسين لشركات تضامنية خدمت السوق الإسلامي. }
$$

ولا يُنسى الدور الذي لعبه الصيارفة في سياسة الإصلاح النقدي في خلافة عبد الملك بن مروان (65هـ/648م-86هـ/605م) إذ قاموا بسحب العملات النقدية وإرساها إلى دور ضرب النقود لتضرب على النمط الإسلامي.

وهكذا كان من الطبيعي إذاً أن يكون للصيارفة أسواق في كل مدينة، بل أن تكون لمم مصارف خاصة وأن يكون لبعض المصارف فروع في المدن الأخرى. وبذلك كانت المصارف بمثابة حلقة وصل |قتصادية بين المدن الإسلامية.

ويمكن القول من خلال الاعتماد على وظيفة الصيرفة إنّا قريبة الشبه بالبنوك والمصارف الحديثة؛ أي أن الصيارفة كانوا يقومون إلى حد ما بما تقوم به المصارف في الوقت الحاضر من مهام، كتحويل العملات وصرف الصكوك 
والسفاتج وتقويم النقود وقبول الودائع وغيرها. على أن الصيرفة في الدولة الإسلامية تختلف من حيث

طبيعة العمل عن المصارف الحديثة إذ إثّا لا تتعامل بالفائدة (الربا) وكانت هناك رقابة إدارية صارمة للحيلولة دون ارتكاب الصيارفة لمخالفات شرعية في التعامل المصري. 